\title{
Islanding Detection in Microgrids Using Harmonic Signatures
}

\author{
Julia Merino, Student Member, IEEE, Patricio Mendoza-Araya, Member, IEEE, \\ Giri Venkataramanan, Senior Member, IEEE, and Mustafa Baysal, Member, IEEE,
}

\begin{abstract}
In the recent years, there has been a growing interest in incorporating microgrids in electrical power networks. This is due to various advantages they present, particularly the possibility of working in either autonomous mode or grid-connected, which make them highly versatile structures for incorporating intermittent generation and energy storage. However, they pose safety issues in being able to support a local island in case of utility disconnection. Thus, in the event of an unintentional island situation, they should be able to detect the loss-of-mains and disconnect for self-protection and safety reasons. Most of the anti-islanding schemes are implemented within control of single generation devices such as dc-ac inverters used with solar electric systems are incompatible with the concept of microgrids due to the variety and multiplicity of sources within the microgrid. In this paper a passive islanding detection method based on the change of the $5^{\text {th }}$ harmonic voltage magnitude at the point of common coupling between grid connected and islanded modes of operation is presented. Hardware test results from the application of this approach to a laboratory scale microgrid are shown. The experimental results demonstrate the validity of the proposed method, in meeting the requirements of IEEE 1547 standards.
\end{abstract}

Index Terms-Harmonic signature, Islanding detection method, Microgrid

\section{INTRODUCTION}

A nti-islanding is an important operational requirement that has been developed in integrating distributed generation to a large centralized electrical network. In the event of an unscheduled outage in the electrical grid, a distributed generation device may continue supplying the local loads by forming an island. In this condition, the local loads remain energized, but the grid's centralized control system may not have capability to regulate the island, precluding any utility operations personnel from performing corrective functions to restore power in a safe manner. Thus, interconnection codes have been developed to

Manuscript received January 14, 2014. This work has been partially funded by the Spanish Ministry of Economy and Competitiveness under the grant BES-2010-034386; the United Technologies Research Center through Professional Services Agreements numbered PSA-1159925 under United States Government Contract Number W912HQ-09-C-0055, and PSA1169296 under United States Government Contract Number DE-EE0003954; TUBITAK-BIDEB 2219 programme; and by CONICYT/FONDAP/15110019.

J. Merino is with the Department of Electrical Engineering, Technical University of Madrid, 28006 Spain, e-mail: julia.merino@upm.es.

J. Merino is also with the Smart Grids and Energy Storage Area of Tecnalia R\&I, Derio, E-48160 Spain, email: julia.merino@tecnalia.com

P. Mendoza-Araya is with the Electrical Engineering Department, Energy Center, University of Chile, Santiago, Chile, e-mail: pmendoza@ing.uchile.cl

G. Venkataramanan is with the Department of Electrical and Computer Engineering, University of Wisconsin, Madison, WI 53706 USA (e-mail: giri@engr.wisc.edu)

M. Baysal is with Yildiz Technical University, Department of Electrical Engineering, Istanbul, Turkey, e-mail: baysal@yildiz.edu.tr ensure that any distributed generation device connected to the grid will disconnect in the event of an outage in the utility within a specified interval of time [1]. On the other hand, a microgrid is a local electrical network that (1) comprises power generation sources, loads, and a means of delivering power from the generation units to the loads, (2) may be connected to a larger utility power system, and (3) operates to balance the power supply and demand within the microgrid. The microgrid paradigm is rapidly emerging as a flexible approach to aggregate diverse distributed and intermittent renewable energy sources and storage devices with the electric grid in a safe and reliable manner. As such a microgrid may operate in both islanded mode or grid-connected mode. Since a microgrid is intentionally designed to support local loads in island mode, traditional anti-islanding approaches pose a conundrum. This paper proposes an operating methodology that defines responsibility centers for anti-islanding protection in microgrids, and presents a viable and practical procedure to realizing anti-islanding protection to ensure a safe operating protocol to overcome this conundrum.

In Section II of this paper, an extensive summary of various islanding detection schemes, along with extensions to microgrids is presented. Section III presents the proposed islanding detection based on harmonics signatures, along with a basis for the proposed approach. Validation of the approach based on experimental tests is discussed in Section IV. Finally, a summary of the results of the work is presented in Section V.

\section{IsLANDING DETECTION METHODS}

Islanding detection methods (IDMs) are numerous and it is easy to find in the literature detailed classifications and reviews. At the outset IDMs can be classified as remote or local. Remote detection methods are under the authority of the system operator and they are located at the utility level. These techniques are generally quite reliable but their implementation is rather expensive and typically reserved for large scale units with extensive SCADA systems well integrated with utility control systems, and thus are not compatible with the vision of microgrids. On the other hand, local detection methods are directly implemented at each generator. Traditionally they have been located inside the inverters used with solar electric systems. Local detection methods can be further split in two main categories: passive and active.

\section{A. Passive methods}

Passive methods are those where measurement and monitoring of a significant magnitude is needed in order to per- 
form the detection, adjusting the protection system thresholds, but without any control action over the rest of the system. Some simple methods are rooted in the analysis of a single magnitude. This is the case of traditional methods such as: over/under frequency [2] unusual change of active power, frequency [3], voltage [2], reactive power [4], jumps in the voltage phase [5] or phase angle difference [6]. In case of a generation-load imbalance produced by an islanding event, fluctuations in these measurements can be easily detected. New research of passive IDMs procedures have also been defined applying highly topical tools like wavelet transform [7], neural networks or decision trees [8]. Different methods which relate more than one quantity can also be found, such as [9] where simultaneous changes in frequency and active power are analyzed or variations produced at the PCC in both the voltage imbalance and the current THD [10] among many others. The main disadvantage passive methods shall present is an significant non-detection zone (NDZ), certain regions in the real/reactive power plane in which variations in voltage and frequency levels can be so small to be undetectable.

\section{B. Active methods}

Active methods introduce an additional external variable, a controlled change or a positive feedback to detect the islanding condition. They are much more effective than the passive ones, and generally do not feature any NDZs. However, they are not as fast as some passive methods because of the system's inherent reaction time, and the implementation cost of this kind of methods is unquestionably higher. It is quite common to find examples of methods based on injection of a signal with a specific frequency [11]: by measuring the impedance at that frequency, the islanding condition can be detected [12]. Some other examples introduce a positive feedback to cause perceptible changes in phase [13] or in voltage [14]. Other solutions are founded on the use of Phase-Locked loop circuits (PLLs), by introducing a disturbance in the inverter reference or in the inverter output. In case of islanding, phase in voltage or in current wave moves out a threshold value causing the inverter to trip [15], [16]. More detailed summaries of these approaches may be found in [17], [18], [19], particularly those that combine both active and passive techniques.

\section{Extension of IDMs to microgrids}

The IDMs defined above have generally been motivated by the early efforts to integrate distributed generation units into electrical grids through an inverter, particularly for solar electric systems. Therefore, these methods are usually thought to be directly implemented within the inverter based source. However, it is necessary to carefully extrapolate the islanding detection concepts in extending the concepts to next steps in technology evolution. The first natural step in the technology evolution is the extension of single inverter-based concepts to the multiple-inverter case. This aspect is well documented in technical literature [20], [21], [22]. In such multi-inverter scenarios, each inverter has an islanding detection responsibility within itself. These extensions do not necessarily introduce new IDM concepts, but takes the complexity of interaction among the different inverters at the same point of common coupling (PCC). The next more nuanced step in technology evolution is the development of integration of heterogenous sources such as solar electric systems, wind generation systems, energy storage systems, micro turbines, combined heat and power systems (CHP) based on fossil fuels, fuel cell systems, etc. with the electric grid using the paradigm of microgrids.

There are some characteristics that establish differences when extending IDMs between the single-inverter and the multi-inverter case to microgrid case. First of all, a microgrid can exchange power bidirectionally with the utility grid. Due to this fact, the detection of islanding events represents a challenge because there are no specific tests requirements defined in the IEEE 1547 standards to deal with such conditions. Secondly, in the event of unintentional island, the microgrid has to be disconnected at the defined point of interconnection to the utility grid as a whole, but not at each generation and/or storage device. Otherwise, it would defeat the microgrid concept. While some of the recent technical literature referring to IDM in microgrids, [23], [24], [25], [26], [27], they are all generally based on simulations of wellmodeled systems within reasonably regulated model scenarios. While [24] presents an experimental model, it is demonstrated only in a single-inverter source connected to the utility grid, thereby limiting the system level extension. Furthermore, these IDMs place a focus on the islanding detection, but leave out the issue of maintaining the intentional island intact after the disconnection event.

It is therefore the intent of this paper to present a novel solution of IDMs as applied to microgrids. It is centered on the detection of loss of mains at the utility interconnection point, where 1547 interconnection regulations are applied, and not at each distributed generation or storage device within the microgrid, which may or may not consist of inverter based generation. None of the generation devices within the microgrid are required to have any traditional anti-islanding technique within their controls. Section III further outlines this approach, that has been verified in extensive tests in a laboratory scale microgrid with multiple heterogenous sources and the RLC load defined by the IEEE Std. 1547 for testing islanding detection schemes. Moreover, the IDM approach and the formation of intentional island within the microgrid and the removal of the unintentional island upstream are all implemented using commercial utility grade relaying equipment.

\section{ISLANDING DETECTION METHOD BASED ON HARMONICS SIGNATURES}

In the proposed methodology, the responsibility of detection of the islanding phenomena and the subsequent disconnection of the microgrid at the point of connection relies, not in the inverters or any other generators present within the microgrid, but in the controls that are incorporated in the switching element at the point of interconnection. The switching element would nominally be operated to ensure appropriate relaying functions such as over-voltage/under-voltage, overfrequency/under-frequency, reverse power, imbalance, synchronism check, etc. at the point of connection. It is therefore, 
natural that the anti-islanding function also become part of the control responsibilities of the relaying device. This is, in fact, a very practical solution to islanding detection in microgrids that is compatible with existing utility relay equipment practices, while removing the burden of islanding detection away from the inverters and generator equipment and integrating this functionality into the PCC equipment. Such an approach would also be readily compatible to emerging technologies such as smart grids and allow the penetration of distributed resources with fewer barriers at various load locations. Fig. 1 presents the proposed microgrid anti-islanding responsibility in contrast with classical 1547 interconnection standard that requires the generation resource to incorporate anti-islanding compliance.

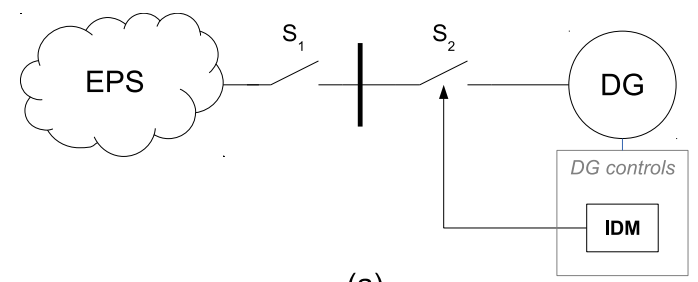

(a)

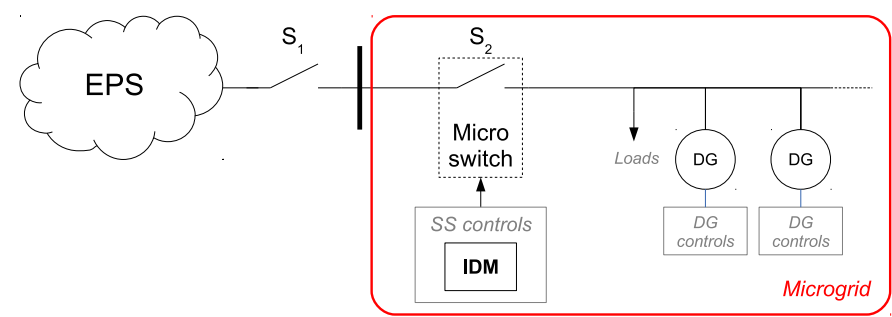

(b)

Fig. 1. Responsibility of anti-islanding functions in (a) classical 1547 distributed generators and (b) microgrids

In this scenario, two operating conditions may be considered. In the first one, there is substantial amount of export or import of power (real and/or reactive) may be taking place at the point of interconnection. In this case, when a network outage occurs, there will be measurable change in voltage and/or frequency at the point of connection due to the natural droop characteristics of the sources within the microgrid. Thus, the classical relay settings would enable disconnection of the switching element, and the upstream island will be disabled, while maintaining the microgrid intact. In the second operating condition, the import and/or export of power at the point of interconnection is less than the threshold conditions for the classical relaying equipment, and the system operation is in the NDZ. Within NDZ compliance testing of islanding detection and successful implementation of anti-islanding is established in the presence of an exactly matched resistive load with a shunt connected L-C tank tuned to be resonant at $60 \mathrm{~Hz}$, such that the power flow through the interconnection switch is nulled [1]. Fig. 2 illustrates the equivalent circuit of the compliance testing for anti-islanding. Microgrid operating conditions are set up to have rated amount of power flow through $S_{2}$, to support the power requirements of $R$. Power throughput through $S_{1}$ null. Disconnection of Switch $S_{1}$ causes a loss of mains when needs to be detected and $S_{2}$ should be turned off within 2 seconds for compliance.

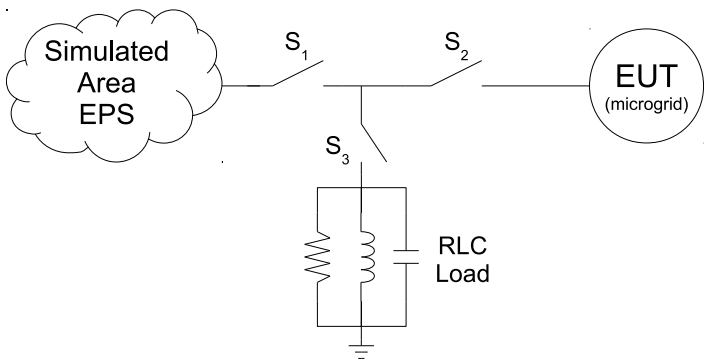

Fig. 2. Equivalent circuit illustrating compliance testing of 1547 antiislanding

To detect the island within NDZ case the method of harmonic signatures is further developed herein. Relationship between harmonic impedance of a network and the network configuration is well known, and a few of the recent IDM methods are based on this aspect [22], [23], [28]. However, these techniques rely on the injection of a particular harmonic component through a perturbation in the power circuit through an inverter. In the presence of multiple inverters and/or classical rotating machine generators, it is not clear how this responsibility will be shared without operating conflicts among them. The techniques call for master-slave designation among the generators within the microgrid, which is fundamentally antithetic to the paradigm of microgrids, where a peer-topeer approach is preferred. Alternatively, the overwhelming presence of small ambient harmonics in a distribution network, both at customer buses and at the substations have been well-documented through various field tests and surveys, particularly the $5^{\text {th }}$ harmonic content in both voltages and currents [29], [30], [31]. The proposed approach relies upon this naturally occurring ambient harmonic content as described further.

\section{A. Ambient harmonics}

Electrical distribution systems are generally rich in harmonics stemming from the presence of nonlinear loads such as rectifiers, compact fluorescent lamps, slightly unbalanced three phase circuit elements like transformers, magnetic saturation in electromagnetic devices, etc. Customers are big contributors of power quality problems in modern power systems, accounting for harmonics, poor power factor and flicker, among others [32, Ch.1]. Several sources of harmonics, such as rectifiers, inverters, switch-mode power supplies and energysavings lamps, easily appear in a microgrid environment. This is specially true for microgrids with strong penetration of inverter-based sources. Even though several modern inverters use filters that mitigate most of the voltage distortion, there still exist freedom at the consumer end to utilize power electronics based equipment which may contribute on the whole to the harmonics existence. Field data on harmonic measurements indicate a $1-3 \%$ persistent harmonic levels present in distribution systems [33], [34], [35]. 


\section{B. Harmonic interactions}

The relative amounts of current and voltage harmonics at a location in a network depends on the network topology as well as the source of harmonic interactions. Based on extensive field test data from various locations in various scenarios over several years, $5^{\text {th }}$ harmonic content in voltage and currents have been found to be persistent and in substantial measurable amounts in customer buses, medium voltage buses as well in substations. This is true for the traditional structures of power systems mainly based on conventional energy sources. But the progressive replacement of conventional generators by converter-based DG sources has increased the pre-existing $5^{\text {th }}$ harmonics levels in microgrid topologies [36], [37]. This will cause a noticeable change in the $5^{\text {th }}$ harmonic signature, suggesting that this variable could be used for islanding detection purposes. The harmonic signatures, either current or voltage, at the PCC will exhibit identifiable differences between the grid-connected and autonomous modes of operation due to the vastly different structures in both cases. Fig. 3 shows the simplified equivalent circuit specified at the $5^{t h}$ harmonic frequency $(300 \mathrm{~Hz}) . I_{\mu G}^{5^{t h}}$ represents the current flowing through $S_{2}$, and $I_{L}^{5^{t h}}$ is the $5^{\text {th }}$ harmonic current flowing through the upstream load and the resonant tank. $V_{\mu G}^{5^{t h}}$ is the equivalent voltage from the utility grid, and $I_{G}^{5^{t h}}$ is the current flowing through $S_{1}$. It is clear from the circuit that when $S_{1}$ becomes open, the ambient harmonics at $S_{2}$ will vary due to network variations.

These differences may be observed and learned by the microswitch.

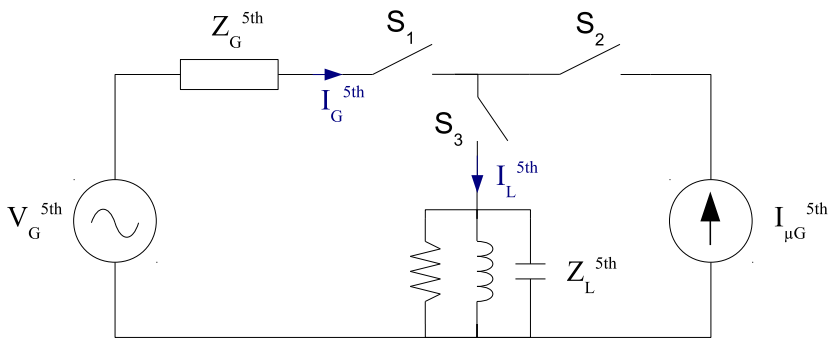

Fig. 3. Equivalent circuit of the system at the fifth harmonic

The simple expressions to determine the $5^{\text {th }}$ harmonic voltage magnitude present at $S_{2}$, when $S_{1}$ is closed and when $S_{1}$ is open are shown in (1) and (2) respectively.

$$
\begin{gathered}
V_{P C C-G}^{5^{t h}}=V_{G}^{5^{t h}} \cdot \frac{Z_{L}^{5^{t h}}}{Z_{G}^{5^{t h}}+Z_{L}^{5^{t h}}}+I_{M G}^{5^{t h}} \cdot Z_{G}^{5^{t h}} \| Z_{L}^{5^{t h}} \\
V_{P C C-I}^{5^{t h}}=I_{M G}^{5^{t h}} \cdot Z_{L}^{5^{t h}}
\end{gathered}
$$

It can be observed that the change in the $5^{\text {th }}$ harmonic voltage depends directly on the relationship between the harmonic impedance of the network $\left(Z_{G}^{5^{t h}}\right)$, and the load impedance $\left(Z_{L}^{5^{t h}}\right)$, which is a function of the load and resonant tank parameters.

Typical spectra of harmonic components of voltages measured from the experimental UW-Madison laboratory scale microgrid test-bed at $S_{2}$ is illustrated in Fig. 4 when $S_{1}$ is closed (Grid connected) and $S_{1}$ is open (Autonomous). These measurements were obtained under the scenario where the microgrid and the utility grid are connected with no power exchange through the link. In case of an unintentional islanding event, the undetectable changes in other variables such as voltage or frequency integrate this loading scenario within the NDZ of classical IDMs. As may be observed, the two conditions show significant differences, particularly with respect to the $5^{\text {th }}$ harmonic. While such discrepancies are a complex function of network conditions, they are nevertheless present in any system. Protective relays with harmonic measurement functions may be programmed to detect these conditions and provide a disconnecting function to appropriately meet safety standards without resorting to any perturbing actions within any of the internal microgrid components.

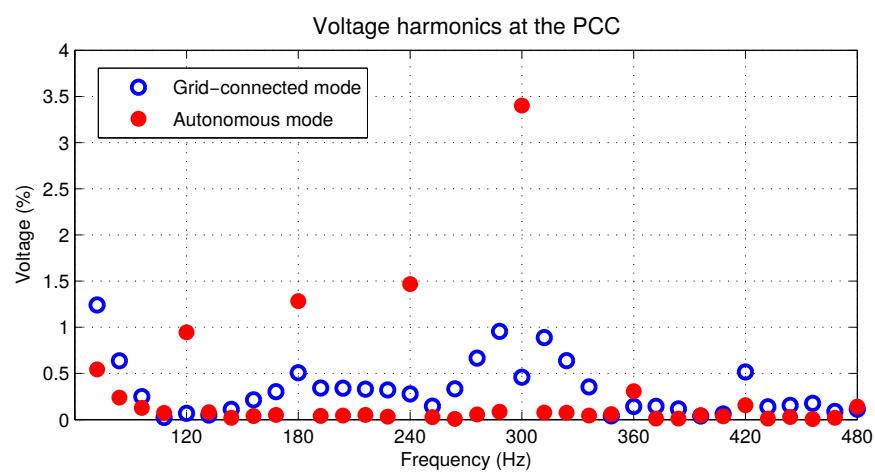

Fig. 4. Typical harmonic voltages under grid-connected and autonomous modes

Based on these preliminary measurements at the location of microgrid interconnection over a period of time, a threshold criteria of $3 \%$ of $5^{\text {th }}$ harmonic voltage content can be defined to ensure positive IDM and anti-islanding. In Fig. 5 a flow diagram of the proposed IDM approach based on the $5^{\text {th }}$ harmonic voltage detection is shown. For instance, the data in Fig. 4 was collected over a long enough period of time (six weeks), at different times of day, both weekdays and weekends and results obtained were similar. Therefore, the spectrum pattern shown can be considered representative of both the harmonic pollution that always exists in the PCC or the $5^{\text {th }}$ harmonic voltage change that occurs as a consequence of an islanding event. Even though the use of $5^{\text {th }}$ harmonic voltage could be extrapolated to other microgrids, an analogous preliminary study should be accomplished to establish the tripping thresholds, which will depend on the specific harmonic characteristics of such microgrids.

\section{EXPERIMENTAL RESULTS}

To demonstrate the validity of the proposed IDM, the necessary tests have been carried out in the lab-scale microgrid installed at UW-Madison. The experimental microgrid is composed by a set of inverted-based sources (microsources) and a set of resistive loads, along with the corresponding interconnection lines. Each microsource consists of an inverter fed by either a DC source or batteries. They can represent almost any distributed generating source, since most of them 


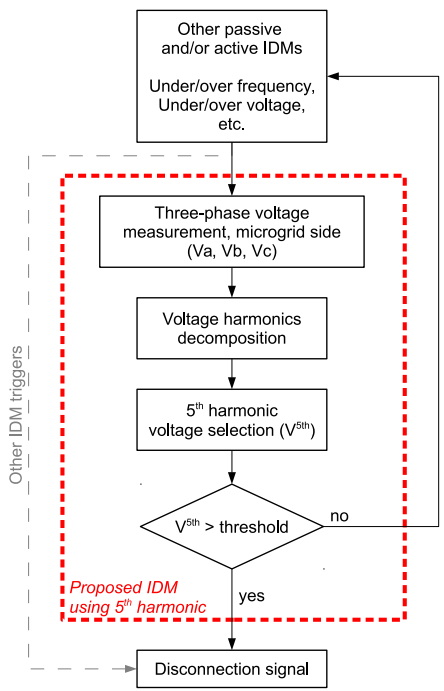

Fig. 5. Flow diagram of the proposed IDM

are connected to the utility grid by means of an inverter. A simplified schematic of the laboratory scale microgrid is shown in Fig. 6.

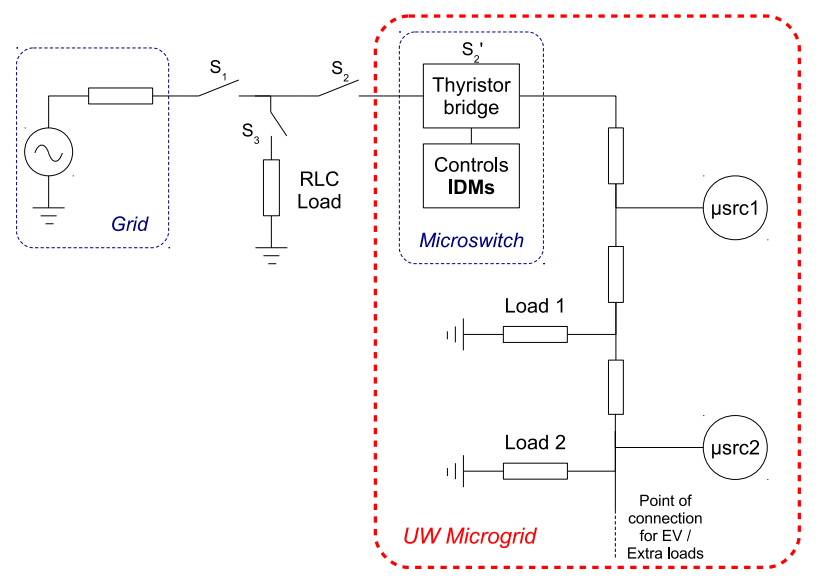

Fig. 6. Simplified diagram of the laboratory scale microgrid

The microsources have a rated power of $15 \mathrm{~kW}$ peak. The resonant RLC load required to perform the test method validation has been calculated according to the expressions appearing in the IEEE 1547.1 standard.

Switch $S_{2}$ is in series with a back-to-back connected thyristor bridge that acts as a solid-state power switch (called $S_{2}{ }^{\prime}$ or "microswitch"), controlled by a firing board, which can be enabled or disabled by a control signal. The switch is managed by a combination of two utility grade commercial relays: the SEL-547 and SEL-735. Both relays exchange information and control signals, while it is the responsibility of the SEL-547 to provide the actuation signal for close or open the static switch. A photograph and simplified schematic diagram of the static switch is shown in Fig. 8. The SEL-547 realizes IDM outside the NDZ using classical under/over frequency (UF/OF) and under/over voltage (UV/OV) trip levels, in addition to synchronization and protection tasks. The NDZ area for the commercial relay SEL-547 has been evaluated through the
Power Mismatch Space method [38] and is displayed in Fig. 7 for first and second tripping thresholds. The operating points inside the area enclosed by the green line represent those with mismatches in active and reactive power that are not appreciable enough to cause the relay tripping.

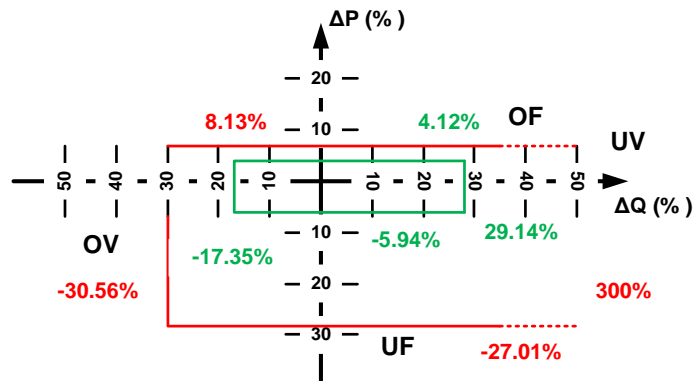

Fig. 7. NDZ for commercial relay SEL-547
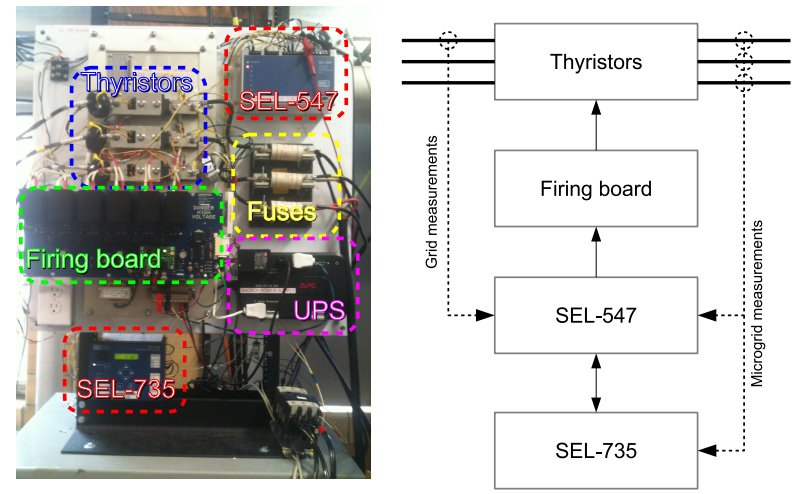

Fig. 8. Photograph of static switch hardware details and interconnection diagram

\section{A. Islanding detection outside the NDZ}

The SEL-547 relay is designed to "offer protection and control elements required by IEEE 1547" [39], and as such, readily includes under- and over-voltage and frequency protection, along with reverse power (motoring), reverse-phase sequence voltage and synchronism check. The static switch utilizes many of these features for the realization of the islanding detection outside the NDZ. However, some of the functionalities are disabled. For example, the reverse power protection is not used, because it is expected for the microgrid to be able to do both importing and exporting of power. Nevertheless, the SEL-547 is a key component in the static switch that allows it to transition the microgrid to either islanded mode or grid-connected mode.

Except for minor modifications, the factory settings of the used relay functions offer compliance with IEEE Std 1547, and were tested on a simulation of the static switch. The islanding detection results are shown in Tables I and II. In these tables, the clearing times (trip times) achieved with the relay are shown, along with the times required by the standard. It can be seen that, for all voltage and frequency ranges, the relay is able to detect the condition and trip under the required time. 
TABLE I

SEL-547 ISLANDIG DETECTION RESULTS: VOLTAGE

\begin{tabular}{cccc}
\hline $\begin{array}{c}\text { Voltage } \\
\text { Range }\end{array}$ & $\begin{array}{c}\text { Testing } \\
\text { voltage [\%] }\end{array}$ & $\begin{array}{c}\text { Average trip } \\
\text { time [s] }\end{array}$ & $\begin{array}{c}\text { IEEE Std 1547 } \\
\text { requirement [s] }\end{array}$ \\
\hline$V<50 \%$ & 45.45 & 0.1145 & 0.16 \\
$50 \% \leq V<88 \%$ & 75.76 & 1.9430 & 2.00 \\
$110 \%<V<120 \%$ & 111.36 & 0.9470 & 1.00 \\
$V \geq 120 \%$ & 121.21 & 0.1170 & 0.16 \\
\hline
\end{tabular}

TABLE II

SEL-547 ISLANDIG DETECTION RESULTS: FREQUENCY

\begin{tabular}{cccc}
\hline $\begin{array}{c}\text { Frequency } \\
\text { range }\end{array}$ & $\begin{array}{c}\text { Testing } \\
\text { frequency }[\mathrm{Hz}]\end{array}$ & $\begin{array}{c}\text { Average trip } \\
\text { time [s] }\end{array}$ & $\begin{array}{c}\text { IEEE Std 1547 } \\
\text { requirement [s] }\end{array}$ \\
\hline$>60.5 \mathrm{~Hz}$ & 61 & 0.0940 & 0.16 \\
$<\{59.8-57.0\} \mathrm{Hz}$ & 58 & 1.9430 & $0.16-300^{\dagger}$ \\
$<57 \mathrm{~Hz}$ & 56 & 0.1010 & 0.16 \\
\hline${ }^{\dagger}$ Adjustable as per IEEE Std $1547-2003, \S 4.2 .4$
\end{tabular}

It is important to remind that, as for the IEEE Std 1547, the ranges of voltages and frequencies stated are considered "abnormal conditions". For the purposes of the islanding detection, these conditions are those under which the static switch should isolate the microgrid from the utility grid, and would not necessarily shut down the microgrid. However, it will be the responsibility of the microgrid operator to maintain the power quality within the microgrid, which could use the same voltage and frequency indices already used for islanding detection. For example, the abnormal frequency range (59.8-57.0) $\mathrm{Hz}$ has an adjustable clearing time, and the use of frequency droop will inevitably drop the frequency under certain conditions, even though this operation mode might be desirable. In the same fashion, a certain voltage drop at the static switch does not necessarily mean that, within the microgrid, the voltages are outside the desired safe operating bands. It will be the task of other relays, such as the SEL-735, to monitor the power quality conditions within the microgrid.

\section{B. Islanding detection inside the $\mathrm{NDZ}$}

The SEL-735 relay has various power quality measurement capabilities which enable IDM using harmonic content resolution. Phase voltages at the terminals of $S_{2}{ }^{\prime}$ are measured and monitored at every cycle. These voltages are decomposed in their harmonic spectra by the SEL-735. Subsequently, the $5^{\text {th }}$ harmonic voltage estimate is compared with the $5^{\text {th }}$ harmonic threshold fixed in the power quality relay settings (set to be $3 \%$ on the basis of a priori background measurements, and per the minimum available threshold of action by SEL-735). If the level measured is over the established threshold, a trip signal is sent to SEL-547 relay. SEL-547 relays this information to open the static switch for full disconnection of the microgrid from any unintended island to upstream loads. The operation of the IDM outside the NDZ and inside the NDZ has been conducted using extensive measurements.

Various tests have been realized for several cases with variable power flows situations. In each case, the power balance from the utility grid and from the microgrid is set to be different. This approach is an extension to the classical IEEE Std 1547, in which the power direction is only flowing from the distributed generation source to the utility grid. Several scenarios for the microgrid have been defined as follows:

1) Microgrid supports RLC load, and exports excess power to grid.

2) Microgrid supports RLC load partially, and utility grid supports balance of power to meet RLC load requirements.

3) Microgrid supports RLC load completely and exports no power to the grid through $S_{1}$.

4) Microgrid imports net power from the utility grid, which also supports RLC load.

5) Microgrid exchanges zero net power through $S_{2}$, while utility grid supports RLC load.

In Table III, a summary of the results for the $5^{\text {th }}$ harmonic voltage amplitude measurements are shown for each of the five scenarios. Scenario 3 is the most critical: there is no clear difference in the fundamental voltage amplitude or frequency when $S_{1}$ opens, because it carries no power (zero fundamental current) and is located within the NDZ area defined in Fig. 7. Sample harmonic patterns under the situation represented by Scenario 3 are shown in Fig. 9, when $S_{1}$ is closed (grid connected) and when $S_{2}$ is open (autonomous). A noticeable difference in the $5^{\text {th }}$ harmonic voltage level between the two conditions is readily apparent. A set of measurement results of the operation of the IDM in the extreme NDZ case of Scenerio 3 with zero power throughput at $S_{1}$ are shown in Table IV.

TABLE III

$5^{\text {th }}$ HARMONIC MEASUREMENTS UNDER DIFFERENT SCENARIOS

\begin{tabular}{|c|c|c|c|c|}
\hline Scenario & $V^{5^{t h}}$ & $S_{1}$ closed $(\%)$ & $V^{5^{t h}}$ & $S_{1}$ open $(\%)$ \\
\hline 1 & & 0.78 & & 3.04 \\
\hline 2 & & 0.74 & & 3.06 \\
\hline 3 & & 0.72 & & 3.54 \\
\hline 4 & & 0.61 & & 3.12 \\
\hline 5 & & 0.69 & & 3.13 \\
\hline
\end{tabular}

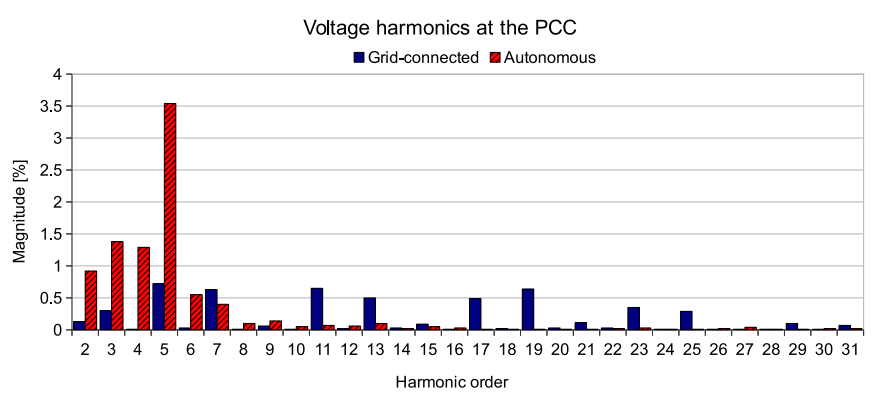

Fig. 9. Voltage harmonics at the PCC under Scenario 3

In the majority of the tests, which were conducted in different days randomly, the proposed IDM approach was able to detect the grid outage event and to act properly. From the results in Table III, it should be noted that in Scenario 3, the harmonic level difference between $S_{1}$ being open and closed is greater than in any other scenario. This renders the proposed method especially useful within the NDZ.

Fig. 10 illustrates the waveforms of three phase voltages and currents measured at the microgrid side terminals of $S_{2}{ }^{\prime}$. 
TABLE IV

SAMPLE OF DETECTION TIMES FOR PROPOSED IDM ALGORITHM

\begin{tabular}{|c|c|c|}
\hline Opening $S_{1}$ & Opening $S_{2}{ }^{\prime}$ & Detection time (s) \\
\hline $21: 14: 05.281$ & $21: 14: 05.605$ & 0.324 \\
\hline $21: 16: 39.527$ & 21:16:39.777 & 0.250 \\
\hline $21: 19: 20.932$ & $21: 19: 21.140$ & 0.208 \\
\hline 21:21:04.446 & 21:21:04.812 & 0.366 \\
\hline 21:22:06.386 & 21:22:06.736 & 0.350 \\
\hline \multirow[t]{2}{*}{$21: 26: 28.160$} & $21: 26: 28.510$ & 0.350 \\
\hline & Average & 0.308 \\
\hline
\end{tabular}

VA, VB and VC are the phase voltages at $S_{2}{ }^{\prime}$, and IA, IB, IC and IN are the phase and neutral currents through $S_{2}{ }^{\prime}$. The first vertical dotted line shows the instant of time when $S_{1}$ was opened. The second vertical dotted line shows the instant of time when $S_{2}{ }^{\prime}$ was opened. From Fig. 10 it can be observed that the voltage waveforms at microgrid side remain intact during the events which establish the viability of the proposed approach.

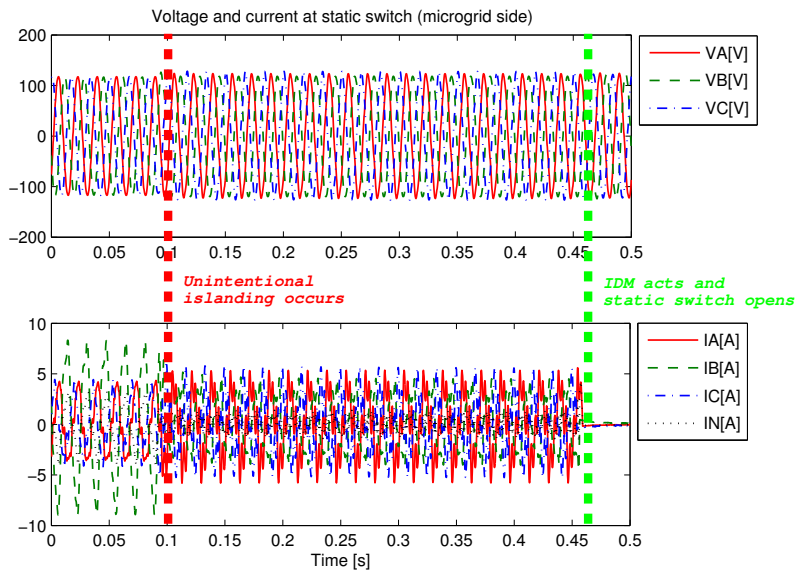

Fig. 10. Voltages in the PCC in grid and microgrid sides and currents through the microswitch

Fig. 10 along with Table IV shows that the time to disconnect is under 2 seconds, which fulfills the IEEE Std 1547 requirement for unintentional islanding.

\section{CONCLUSIONS}

In this paper a simple, low-cost and effective passive method to detect an islanding situation in microgrids has been presented. It is based on the differences produced in the harmonic voltage content before and after the loss of mains event at the point of common coupling. As opposed to other passive techniques, it presents the great advantage of being useful to cover all $\mathrm{P}-\mathrm{Q}$ scenarios, completely eliminating non-detection zones when used in conjunction with other IDMs.

This method has been validated by means of several tests conducted over the UW-Madison microgrid installation. A previous study of the harmonic pattern was accomplished to select the $5^{\text {th }}$ harmonic voltage as the variable of interest for detecting islanding conditions in this microgrid. In section III the suitability of using the $5^{\text {th }}$ harmonic has been well documented, being this harmonic present in both voltages and currents in distribution networks with high penetration of inverter-based sources. The particular characteristics of other microgrids might suggest the employment of other harmonic components, such as $7^{\text {th }}, 11^{\text {th }}$ or $13^{\text {th }}$.

The algorithm successfully disconnected the microgrid under unintentional islanding events under 2 seconds, fulfilling the requirements of the IEEE Std 1547.

While various other active IDM methods have been applied at each distributed generation device such as solar PV inverters, harmonic injection based on high frequency signatures, etc., the proposed approach completely eliminates the need for any modification to the distributed generation device. The responsibility of IDM and conformance to antiislanding requirements are delegated to the protective relay at the interconnection point, which integrates all the IEEE 1547 compliance functions. Such an approach makes integration and adoption of microgrid paradigms for integrating large amounts of sustainable energy generation devices with the central grid more practical and viable while ensuring existing safety protocols during outage and routine maintenance.

\section{ACKNOWLEDGMENT}

We would like to thank to the Wisconsin Electric Machines and Power Electronics Consortium (WEMPEC) by supporting the work at the University of Wisconsin-Madison.

\section{REFERENCES}

[1] "IEEE Standard for Interconnecting Distributed Resources with Electric Power Systems," IEEE Std 1547-2003, pp. 1 -16, 2003.

[2] F. De Mango, M. Liserre, A. Aquila, and A. Pigazo, "Overview of antiislanding algorithms for PV systems. part i: Passive methods," in Power Electronics and Motion Control Conference, 2006. EPE-PEMC 2006. 12th International, 30 2006-sept. 1 2006, pp. 1878 -1883.

[3] A. Aljankawey, W. Morsi, L. Chang, and C. Diduch, "Passive methodbased islanding detection of renewable-based distributed generation: The issues," in Electric Power and Energy Conference (EPEC), 2010 IEEE, aug. 2010, pp. $1-8$.

[4] M. Bakhshi, R. Noroozian, and G. Gharehpetian, "Passive anti-islanding scheme based on reactive power in the smart grids," in Smart Grids (ICSG), 2012 2nd Iranian Conference on, may 2012, pp. $1-7$.

[5] B. Singam and L. Hui, "Assessing SMS and PJD schemes of antiislanding with varying quality factor," in Power and Energy Conference, 2006. PECon '06. IEEE International, nov. 2006, pp. 196 -201.

[6] A. Samui and S. Samantaray, "Assessment of ROCPAD relay for islanding detection in distributed generation," Smart Grid, IEEE Transactions on, vol. 2, no. 2, pp. $391-398$, june 2011.

[7] N. Lidula, N. Perera, and A. Rajapakse, "Investigation of a fast islanding detection methodology using transient signals," in Power Energy Society General Meeting, 2009. PES '09. IEEE, july 2009, pp. 1 -6.

[8] R. Sun, Z. Wu, and V. Centeno, "Power system islanding detection amp; identification using topology approach and decision tree," in Power and Energy Society General Meeting, 2011 IEEE, july 2011, pp. 1 -6.

[9] M. Abdolrasol and S. Mekhilef, "Hybrid anti-islanding algorithm for utility interconnection of distributed generation," in Technical Postgraduates (TECHPOS), 2009 International Conference for, dec. 2009, pp. 1 -5 .

[10] H. Karegar and A. Shataee, "Islanding detection of wind farms by THD," in Electric Utility Deregulation and Restructuring and Power Technologies, 2008. DRPT 2008. Third International Conference on, april 2008, pp. $2793-2797$.

[11] G. Hernandez-Gonzalez and R. Iravani, "Current injection for active islanding detection of electronically-interfaced distributed resources," Power Delivery, IEEE Transactions on, vol. 21, no. 3, pp. 1698 -1705, july 2006.

[12] H. Shi, Z. Yang, X. Yue, L. Hou, and F. Zhuo, "Calculation and measurement of harmonic impedance for a microgrid operating in islanding mode," in Power Electronics and Motion Control Conference (IPEMC), 2012 7th International, vol. 1, june 2012, pp. 356 -361. 
[13] F. Liu, Y. Kang, Y. Zhang, S. Duan, and X. Lin, "Improved SMS islanding detection method for grid-connected converters," Renewable Power Generation, IET, vol. 4, no. 1, pp. 36 -42, january 2010.

[14] H. Zeineldin and M. Salama, "Impact of load frequency dependence on the NDZ and performance of the SFS islanding detection method," Industrial Electronics, IEEE Transactions on, vol. 58, no. 1, pp. 139 -146 , jan. 2011.

[15] D. Velasco, C. Trujillo, G. Garcera, and E. Figueres, "An active antiislanding method based on phase-PLL perturbation," Power Electronics, IEEE Transactions on, vol. 26, no. 4, pp. 1056 -1066, april 2011.

[16] M. Ciobotaru, V. Agelidis, R. Teodorescu, and F. Blaabjerg, "Accurate and less-disturbing active antiislanding method based on PLL for grid-connected converters," Power Electronics, IEEE Transactions on, vol. 25 , no. 6, pp. $1576-1584$, june 2010.

[17] A. Massoud, K. Ahmed, S. Finney, and B. Williams, "Harmonic distortion-based island detection technique for inverter-based distributed generation," Renewable Power Generation, IET, vol. 3, no. 4, pp. 493 -507 , december 2009.

[18] J. Lee, "Islanding Detection Methods for Microgrids," Master's thesis, University of Wisconsin-Madison, USA, 2010.

[19] P. Mahat, Z. Chen, and B. Bak-Jensen, "Review of islanding detection methods for distributed generation," in Electric Utility Deregulation and Restructuring and Power Technologies, 2008. DRPT 2008. Third International Conference on, april 2008, pp. $2743-2748$.

[20] L. Lopes and Y. Zhang, "Islanding detection assessment of multi-inverter systems with active frequency drifting methods," Power Delivery, IEEE Transactions on, vol. 23, no. 1, pp. $480-486$, jan. 2008.

[21] M. Xue, F. Liu, Y. Kang, and Y. Zhang, "Investigation of active islanding detection methods in multiple grid-connected converters," in Power Electronics and Motion Control Conference, 2009. IPEMC '09. IEEE 6th International, may 2009, pp. $2151-2154$.

[22] S. Patthamakunchai, M. Konghirun, and W. Lenwari, "An anti-islanding for multiple photovoltaic inverters using harmonic current injections," in Electrical Engineering/Electronics, Computer, Telecommunications and Information Technology (ECTI-CON), 2012 9th International Conference on, may 2012, pp. $1-4$.

[23] L. Jun, H. Xue-liang, C. Xiao-hu, X. Miao, and X. Wen, "Two islanding detection circuits based on the impedance variation for the micro-grid," in Power Electronics for Distributed Generation Systems (PEDG), 2010 2nd IEEE International Symposium on, june 2010, pp. 859 -863.

[24] X. Wang, C. Zhang, W. Zhao, and X. Mu, "Non-devastating islanding detection for micro-grid based on mathematical statistics," in Power Electronics and ECCE Asia (ICPE ECCE), 2011 IEEE 8th International Conference on, 30 2011-june 3 2011, pp. 2650 -2657.

[25] Y.-G. Lee, H.-W. Lee, Y.-H. Kim, T.-Y. Zheng, and Y.-C. Kang, "Islanding detection for a micro-grid based on the active and reactive power in the time domain," in Advanced Power System Automation and Protection (APAP), 2011 International Conference on, vol. 3, oct. 2011, pp. $1956-1961$

[26] H. Bitaraf, M. Sheikholeslamzadeh, A. M. Ranjbar, and B. Mozafari, "A novel SVM approach of islanding detection in micro grid," in Innovative Smart Grid Technologies - Asia (ISGT Asia), 2012 IEEE, may 2012, pp. $1-5$.

[27] J. Li, X. Li, Y. Zhang, S. Hao, and Y. Jia, "A centralized injection method for islanding detection in micro-grids," in Power and Energy Engineering Conference (APPEEC), 2012 Asia-Pacific, march 2012, pp. $1-3$.

[28] D. Reigosa, F. Briz, C. Blanco, P. Garcia, and J. Guerrero, "Active islanding detection using high frequency signal injection," in Energy Conversion Congress and Exposition (ECCE), 2011 IEEE, sept. 2011, pp. $2183-2190$.

[29] A. Emanuel, J. Orr, D. Cyganski, and E. M. Gulachenski, "A survey of harmonic voltages and currents at distribution substations," Power Delivery, IEEE Transactions on, vol. 6, no. 4, pp. 1883-1890, 1991.

[30] —, "A survey of harmonic voltages and currents at the customer's bus," Power Delivery, IEEE Transactions on, vol. 8, no. 1, pp. 411-421, 1993.

[31] I. Nejdawi, A. Emanuel, D. Pileggi, M. J. Corridori, and R. D. Archambeault, "Harmonics trend in ne usa: a preliminary survey," Power Delivery, IEEE Transactions on, vol. 14, no. 4, pp. 1488-1494, 1999.

[32] M. A. S. M. Ewald F. Fuchs, Power Quality in Power Systems and Electrical Machines. Elsevier Academic Press, 2008.

[33] J. F. G. Cobben, W. L. Kling, and J. M. A. Myrzik, "Power quality aspects of a future micro grid," in Future Power Systems, 2005 International Conference on, 2005, pp. 5 pp.-5.
[34] S. Bhattacharyya, J. F. G. Cobben, and W. Kling, "Harmonic current pollution in a low voltage network," in Power and Energy Society General Meeting, 2010 IEEE, 2010, pp. 1-8.

[35] P. Lauwers, C. Pirenne, P. Sommereyns, W. Vancoetsem, E. De Jaeger, and M. De Witte, "Power quality monitoring in belgian distribution networks," in Electricity Distribution, 2005. CIRED 2005. 18th International Conference and Exhibition on, 2005, pp. 1-6.

[36] A. Kahrobaeian and Y.-R. Mohamed, "Interactive distributed generation interface for flexible micro-grid operation in smart distribution systems," Sustainable Energy, IEEE Transactions on, vol. 3, no. 2, pp. 295-305, April 2012.

[37] V. Pandi, H. Zeineldin, and W. Xiao, "Allowable dg penetration level considering harmonic distortions," in IECON 2011 - 37th Annual Conference on IEEE Industrial Electronics Society, Nov 2011, pp. 814-818.

[38] Z. Ye, A. Kolwalkar, Y. Zhang, P. Du, and R. Walling, "Evaluation of anti-islanding schemes based on nondetection zone concept," Power Electronics, IEEE Transactions on, vol. 19, no. 5, pp. 1171-1176, Sept 2004.

[39] SEL-547 - Utility-Grade Protection for Distributed Generation, Schweitzer Engineering Laboratories, Inc. (SEL), 2013. [Online]. Available: https://www.selinc.com/WorkArea/DownloadAsset.aspx?id=2882

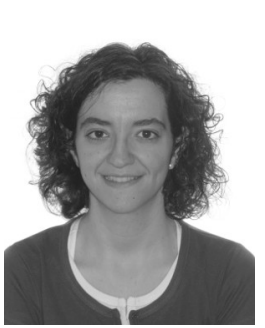

Julia Merino (IEEE Student Member) was born in Spain. She received the Dipl. degree in industrial engineering and the M.S. degree in electrical engineering from the Technical University of Madrid, Madrid, Spain, in 2010 and 2012, respectively. She is currently working towards the Ph.D degree. She is also involved in the Smart Grids and Energy Storage Area in Tecnalia R\&I Corporation. Ms. Merino is the actual Vice Chair of the IEEE WIE Spanish Section.

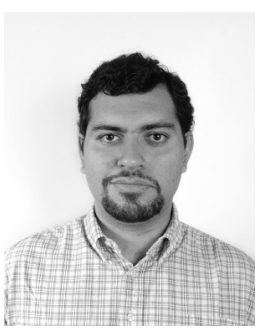

Patricio Mendoza-Araya (IEEE Member) was born in Chile. He received the B.Sc. degree in electrical engineering from the University of Chile in 2007 , and the Ph.D. degree from the University of Wisconsin-Madison in 2014. He is currently an instructor in the Electrical Engineering Department of the University of Chile. His research field is power electronics on microgrids, electric vehicles and renewable energies.

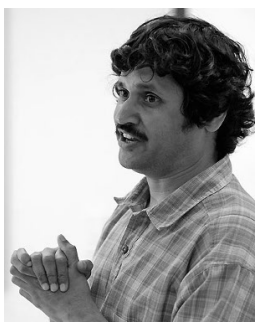

Giri Venkataramanan (M'92-SM'06) received the B.Sc. degree in electrical engineering from the Government College of Technology, Coimbatore, India, the M.Sc. degree from the California Institute of Technology, Pasadena, and the Ph.D. degree from the University of Wisconsin, Madison. After teaching electrical engineering at Montana State University, Bozeman, he returned to University of Wisconsin, Madison, as a Faculty Member in 1999, where he continues to direct research in various areas of electronic power conversion as an Associate Director of the Wisconsin Electric Machines and Power Electronics Consortium (WEMPEC). He holds four U.S. patents and has published a number of papers.

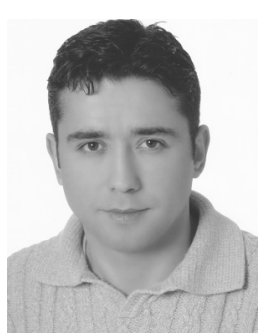

Mustafa Baysal was born in Istanbul, Turkey in 1976. He received B.Sc., M.Sc. and Ph.D. degrees all from Yildiz Technical University,Department of Electrical Engineeringin 1998, 2001 and 2008, respectively. Currently, he is an Assistant Professor in the Yildiz Technical University. His current research interests include microgrids, smart grids, distributed generation, power quality and application of power electronics to power systems. 